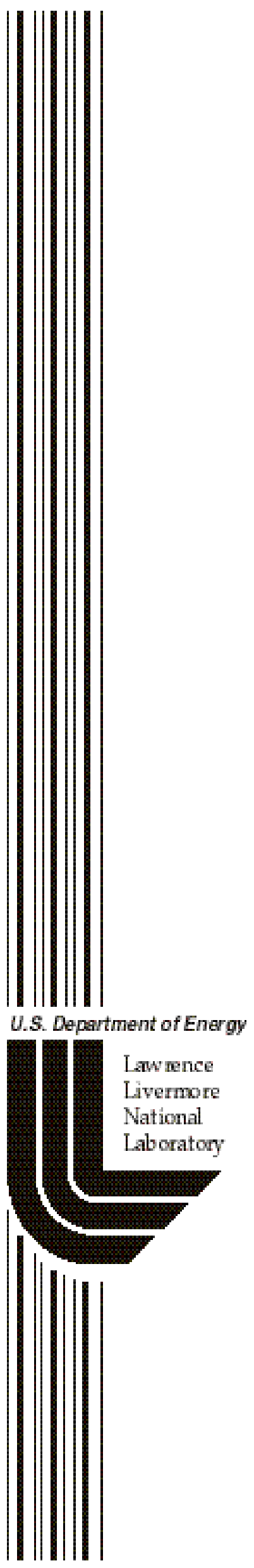

UCRL-ID-142803

\title{
Low Charge-state AMS for Biological Research
}

John S. Vogel, Theodore Ognibene, Mark Roberts, Thomas Brown, Andrew Clifford, Daniel Espinosa, Yumei Lin

\section{March 1, 2001}




\section{DISCLAIMER}

This document was prepared as an account of work sponsored by an agency of the United States Government. Neither the United States Government nor the University of California nor any of their employees, makes any warranty, express or implied, or assumes any legal liability or responsibility for the accuracy, completeness, or usefulness of any information, apparatus, product, or process disclosed, or represents that its use would not infringe privately owned rights. Reference herein to any specific commercial product, process, or service by trade name, trademark, manufacturer, or otherwise, does not necessarily constitute or imply its endorsement, recommendation, or favoring by the United States Government or the University of California. The views and opinions of authors expressed herein do not necessarily state or reflect those of the United States Government or the University of California, and shall not be used for advertising or product endorsement purposes.

This work was performed under the auspices of the U. S. Department of Energy by the University of California, Lawrence Livermore National Laboratory under Contract No. W-7405-Eng-48.

This report has been reproduced directly from the best available copy.

Available electronically at http://www.doc.gov/bridge

Available for a processing fee to U.S. Department of Energy

And its contractors in paper from

U.S. Department of Energy

Office of Scientific and Technical Information

P.O. Box 62

Oak Ridge, TN 37831-0062

Telephone: (865) 576-8401

Facsimile: (865) 576-5728

E-mail: reports@adonis.osti.gov

Available for the sale to the public from

U.S. Department of Commerce

National Technical Information Service

5285 Port Royal Road

Springfield, VA 22161

Telephone: (800) 553-6847

Facsimile: (703) 605-6900

E-mail: orders@ntis.fedworld.gov

Online ordering: http://www.ntis.gov/ordering.htm

OR

Lawrence Livermore National Laboratory

Technical Information Department's Digital Library

http:/ / www.llnl.gov/tid/Library.html 


\section{Low Charge-state AMS for Biological Research}

Final Report: 98 ERI-012

\section{LLNL Personnel:}

John S. Vogel

Theodore Ognibene

Mark Roberts

Thomas Brown

\section{University Faculty}

Andrew Clifford

Department of Nutrition

University of California

Davis, CA 95616

\section{Students \& Post Docs}

Daniel Espinosa, San Jose State University Yumei Lin, UC @ Davis

\section{Purpose}

University collaborations and internal research programs that trace isotopically labeled compounds in natural biological systems have grown significantly in the past few years. New research in molecular nutrition, protein sequencing, immunoassays, and toxicology now require hundreds to thousands of sample analyses per project. The goal of this effort was to strengthen this Laboratory and University health related research by the expansion of AMS access. This was achieved by our design and implementation of an AMS spectrometer that analyzes isotopic ions at lower energies in a more compact spectrometer without sacrificing precision or throughput. The decrease in ion energies is accompanied by a significant reduction in size and cost of the spectrometer. Our successful reduction in spectrometer cost, operation, and space will make this technology more appealing to research institutions, including industrial research centers. While others have also developed smaller spectrometers, these are limited in precision and throughput by the much lower intensities of ion beams that can be transmitted through them without differential loss of isotope species. The primary challenge in this project was mating the LLNL-designed high intensity negative ion 
source (Roberts, et al. 1994; Southon \& Roberts, 2000) to available accelerator components and then showing that the precision and throughput would remain high enough to serve the research that needs large numbers of AMS analyses. The project also required reduction in operating complexity so that scientists and students would not require technical specialists to make their measurements. This report describes the experiments done to assure the needed spectrometer performance.

\section{Activities}

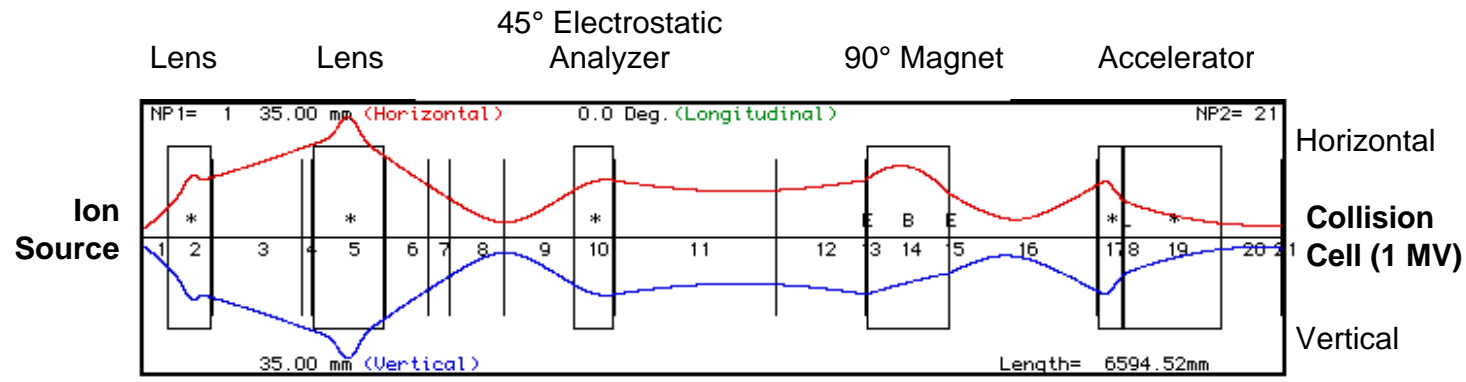

Figure 1. The final ion optics design of a set of lenses and transport that appeared capable of bringing the full ion output of the LLNL ion source to a beam size capable of entering the accelerator's collision cell. The lowest trace shows the vertical displacement and the upper trace shows the horizontal displacement from the center line as functions of longitudinal distance from the ion source to the high voltage collision cell.

\section{Discovery of method to analyze intense ion beams}

Accelerator and ion analysis components were obtained from National Electrostatics Corporation (NEC) of Middleton WI. These components were designed to accept ion beams from their proprietary ion source that is a factor of 5 to 10 lower in output than the LLNL-designed source (von Reden, et al. 2000). The greatest restriction appeared to be the injection of the full ion source output into the 1 megaVolt acceleration stage, since space-charge effects tend to broaden an ion beam as the intensity of the ion beam increases. We modeled the ion paths from our ion source to the center of the accelerator using computer programs to discover a way to control this broadening well enough for the desired performance. We found that the instrument could operate well at the lower charge state and higher ion beam intensity, but that some of the ion focussing would be counter to conventional concepts. Figure 1 shows the ion beam envelope as it passes from the ion source (left edge of Figure) to the central part of the accelerator where it enters a collision cell containing diffuse gas that will 
break up molecular isobars of the desired isotope (right edge). The lower envelope line represents the vertical displacement from the spectrometer axis, while the upper trace represents the horizontal displacement, even as the axis itself bends through a $45^{\circ}$ electrostatic analyzer and a $90^{\circ}$ magnet. The ions are seen to cleanly enter the collision cell, but this was found possible only if a "zoom lens" assembly is used to maintain a relatively "fat" ion beam as it transits the electric and magnetic analysis elements. It is the width of the "waist" between the elements that is counter to many spectrometer designs, which often have a well focussed (thin waist) at the magnet's focal image.

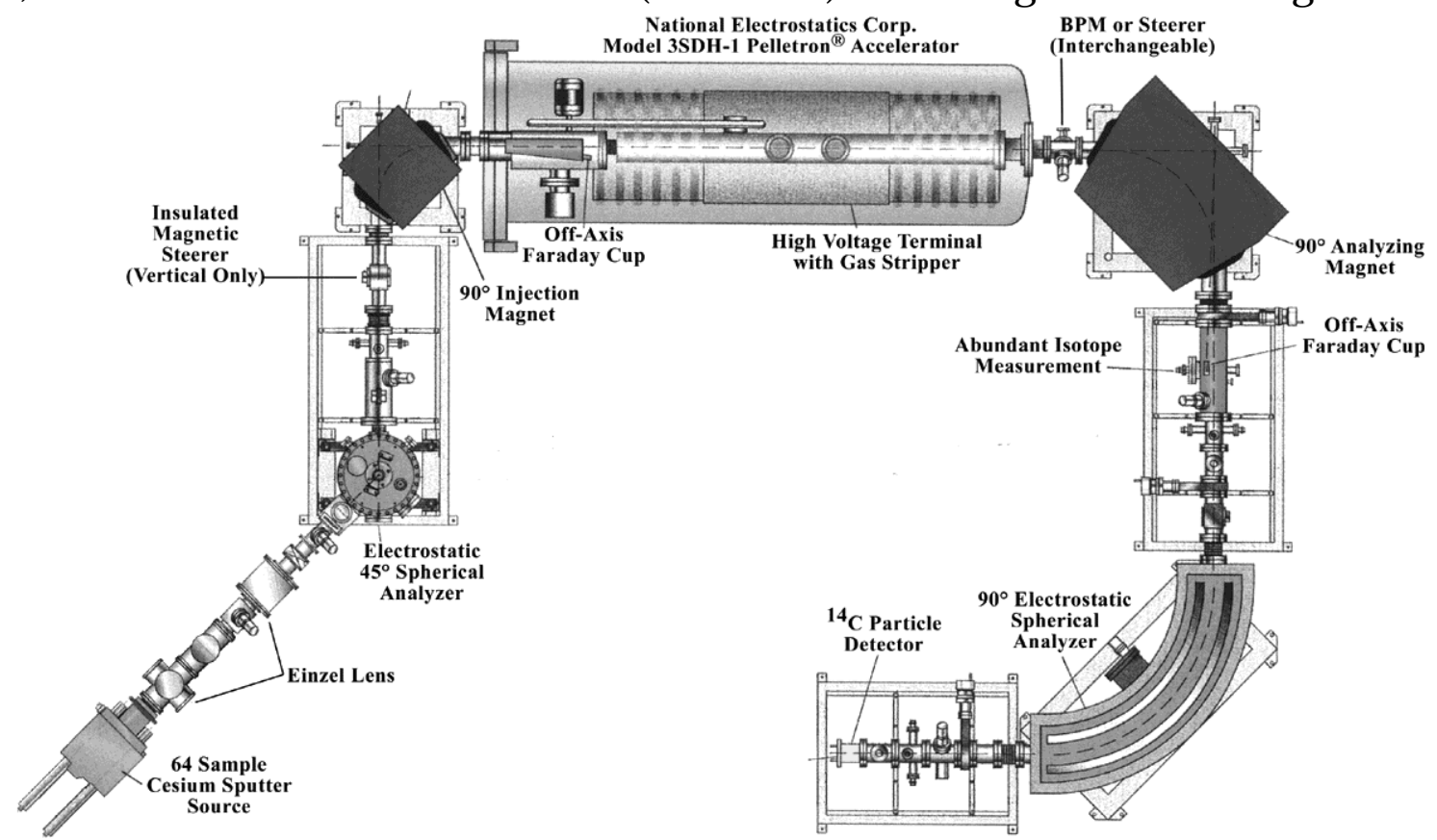

Figure 2. The overall layout of the low charge state spectrometer that combines an LLNL built ion source and control system to spectrometer components obtained from National Electrostatics Corporation. The ion source is on the left and the final ion detector lies near the lower middle. The zoom lens that is capable of transporting high intensity beams through the system with minimal loss is comprised of the einzel lenses at lower left.

\section{Layout of spectrometer components}

With this discovery in hand, the spectrometer was assembled as shown in Figure 2 , which shows the ion source on the left, followed by the two lenses that comprise a zoom structure, the electrostatic analyzer, and the magnetic element prior to the accelerating system that contains the collision cell. After the accelerator, a magnet and electrostatic element are again used to sort out the chosen isotopic ions that have 
changed from a charge of minus one to a charge of plus one from all of the debris from molecular breakup and scattering caused by the collision cell. We explored the ions emerging from the accelerator to determine if a high enough gas pressure could be reached within the collision cell to destroy interfering molecules without having so much ion scattering that our intense starting ion beams would be wasted.

\section{Technical Outcome}

We determined the minimal pressure required to break up all molecules by counting the ions that reached the detector after the large electrostatic element. As the cell pressure rose, the number of transmitted molecular ions decreases, until only atomic ions are left at a constant count rate. This effect is seen in Figure 3 (solid circles) which shows that a constant rate begins at a pressure of about 40 milliTorr in the collision cell. The rate of detector pulses settles at about 1 per second, which is a factor of several hundred lower than the count rate due to samples with natural ${ }^{14} \mathrm{C}$. The overall loss of ions due to scattering out of the correct path due to their collisions with the gas in the accelerator was tested by measuring the ion current of a stable isotope transmitted through the accelerator as a function of cell pressure. The small open circles of Figure 3 show this relationship for a number of different ion source intensities. At the pressure required for molecular destruction, we obtain $35 \%$ of the incident ion beam emerging from the accelerator with a single positive charge, even for the intense ion beams from the LLNL source as installed. This confirms that a small spectrometer operating at a low $(+1)$ charge state transition can have high efficiency and low background levels. Perhaps another $30-40 \%$ of the incident ions emerge at higher charge states $(+2, \ldots)$ and a fraction even emerge with no electrical charge. These other charge states are lost to the analysis, but the $35 \%$ that are retained is comparable to the nearly $50 \%$ that are analyzed by our larger spectrometer at 6.5 million Volts. 


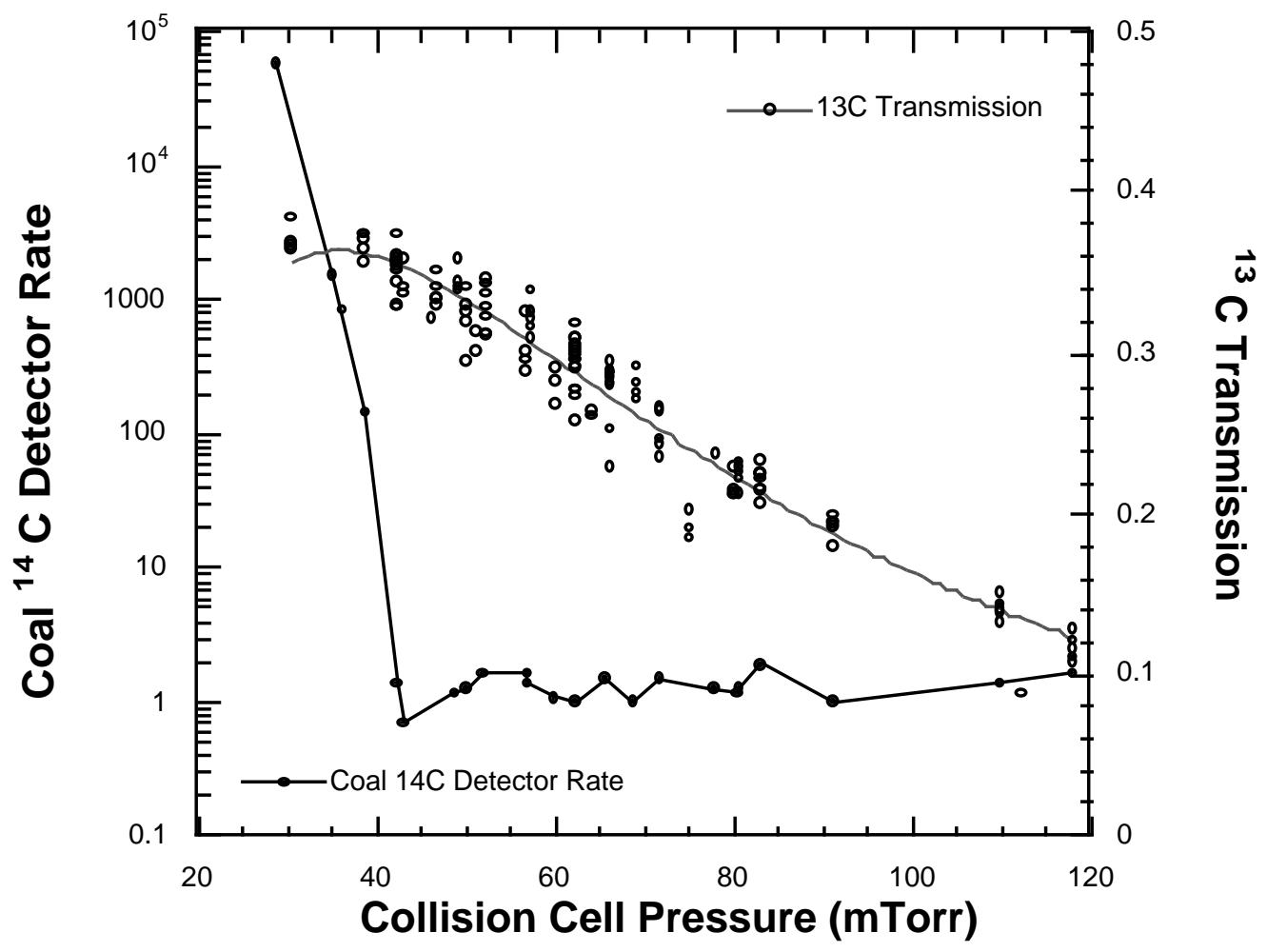

Figure 3. The ${ }^{13} \mathrm{C}$ ion transmission through the acceleration stage and the " ${ }^{14} \mathrm{C}^{\prime \prime}$ count rate at the spectrometer detector are plotted as functions of the pressure of argon gas within the high voltage collision cell. The fall in " ${ }^{14} \mathrm{C}^{\prime \prime}$ count rate is due to more complete breakup of molecular mass 14 ions $\left({ }^{12} \mathrm{CH}_{2}\right.$ and $\left.{ }^{13} \mathrm{CH}\right)$. The best transmission with complete molecular destruction occurs at 45 mTorr pressure.

We explored the identity of the 1 count per second background rate from Figure 3 by scanning the energy selection of the large electrostatic sector when the analysis magnet remained set for the transmission of ${ }^{14} \mathrm{C}$. Figure 4 shows the particle count rate arriving at the detector as a function of the energy band pass of the analyzer. Most particles passing the magnetic analysis are not random events, but are created by distinct processes that are revealed by the peaks at specific energies. The majority of these magnetically analyzed events are products of molecular dissociation in the collision cell. The probable causes of the peaks near the desired ${ }^{14} \mathrm{C}$ peak are noted in Figure 4 . 


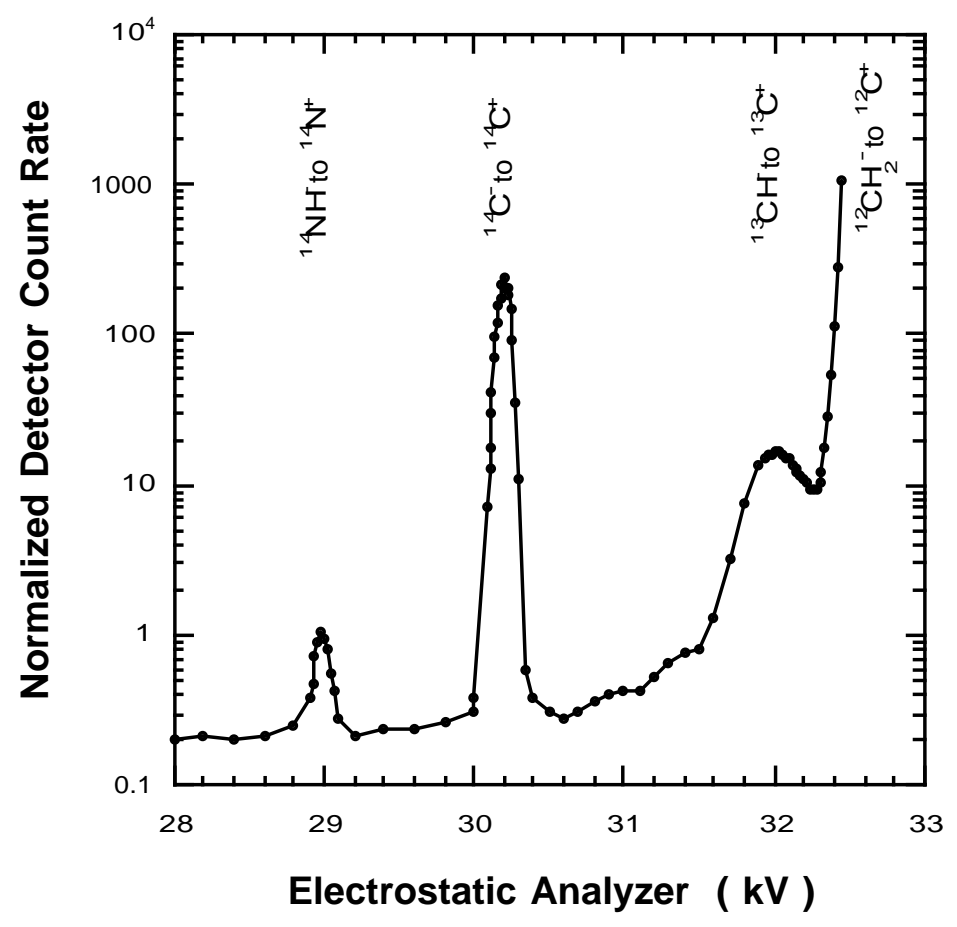

Figure 4. The count rate for particle detection after the final high energy electrostatic analyzer is shown as a function of voltage on the analyzer plates with the analyzing magnet set to transmit the ${ }^{14} C^{+}$. Molecular breakup products form the peaks in count rate, but a scattered component provides about 0.3 counts of the 300 counts per second due to a natural radiocarbon level.

The non-peak related counts found with the ${ }^{41} \mathrm{C}$ peak are ions that scattered on residual gas while the ions were still accelerating after the collision cell. This level was seen to be dependent on the quality of the vacuum in this section of the accelerator. This was tested by doubling the pumping capacity at the high energy analyzing magnet. The observed count rates will not cause sensitivity loss for biochemical and natural level ${ }^{14} \mathrm{C}$ measurements.

As a result of this project, we now have a spectrometer that has the capacity to measure up to 400 samples per 24 hour day, or even 500 per 40 hour week. This is the type of capacity demanded by new research in nutrition, proteomics, clinical chemistry, and other emerging uses of AMS in biological science.

This work was performed in part under the auspices of the U.S. Department 
of Energy by University of California Lawrence Livermore National Laboratory under Contract No. W-7405-Eng-48.

\section{References}

Roberts, M. L., Norman, P. J ., Garibaldi, J . L., Hornady, R. S. (1994) The New LLNL AMS Sample Changer. Nuclear Instruments \& Methods In Physics Research Section B-Beam Interactions With Materials and Atoms. B92: 111-114.

Southon, J .R., Roberts, M.L. (2000) Ten years of sourcery at CAMS/LLNL Evolution of a Cs ion source. Nuclear Instruments \& Methods In Physics Research Section B-Beam Interactions With Materials and Atoms. B172: 257-261.

von Reden, K.F., Bellino, M., Long, P., Schneider, R.J ., Loger, R. (2000) Installation of a 134 sample MC-SNICS ion source at NOSAMS and the first results. Nucl ear Instruments \& M ethods In Physics Research Section B-Beam Interactions With Materials and Atoms. B172: 247-251.

\section{Publications}

Ognibene, T. J., T. A. Brown, J. P. Knezovich, M. L. Roberts, J. R. Southon and J. S. Vogel (2000). "Ion-optics calculations of the LLNL AMS system for biochemical C-14 measurements." Nuclear Instruments \& Methods in Physics Research Section B-Beam Interactions With Materials and Atoms 172: 47-51.

Vogel, J. S. (2000). "Accelerator mass spectrometry for human biochemistry: The practice and the potential." Nuclear Instruments \& Methods in Physics Research Section B-Beam Interactions With Materials and Atoms 172: 884-891.

Ognibene, T.J., Roberts, M.L., Southon, J.R., Vogel, J.S. (2001) Low charge state AMS for high throughput ${ }^{14} \mathrm{C}$ quantification. in Pliess, U. \& Voges, R., eds. Synthesis and applications of isotopically labelled compounds (John Wiley \& Sons, Chichester) v. 7: 515-518. 